\title{
Timing of Technology Adoption and Product Market Competition
}

\author{
Chrysovalantou MiLliou \\ EMMANUEL PETRAKIS
}

CESIFO WORKING PAPER NO. 2686

CATEGORY 11: INDUSTRIAL ORGANISATION

JUNE 2009

Presented at CESifo Area Conference on ApPlied Microeconomics, March 2009

An electronic version of the paper may be downloaded
- from the SSRN website: $\quad$ www.SSRN.com
- from the RePEc website:
from the CESifo website: 


\title{
Timing of Technology Adoption and Product Market Competition
}

\begin{abstract}
This paper examines how product market competition affects firms' timing of adopting a new technology as well as whether the market provides sufficient adoption incentives. It shows that adoption dates differ not only among symmetric firms but also among markets with Cournot and Bertrand competition. More specifically, Cournot competition can lead to earlier adoption than Bertrand competition. It shows also that competition toughness does not always reinforce adoption incentives. When goods are differentiated enough, adoption occurs later than it is socially optimal.
\end{abstract}

JEL Code: L13, O31, O32, O33.

Keywords: technology adoption, innovation, diffusion, product differentiation.

Chrysovalantou Milliou

Department of International and European

Economic Studies

Athens University of Economics and

Business

Greece - 10434 Athens

cmilliou@aueb.gr
Emmanuel Petrakis

Department of Economics

University of Crete

Rethymnon 74100

Greece

petrakis@ermis.soc.uoc.gr

June 2009

This is a substantially revised version of the circulated earlier manuscript "Technology Diffusion in a Differentiated Oligopoly". We wish to thank Helmut Bester, Vivek Ghosal and Praveen Kujal for helpfull comments. Financial support by the Ministerio de Educacion y Ciencia under project SEJ2007-66268 is gratefully acknowledged. Full responsibility for all shortcomings is ours. 


\section{Introduction}

Technological progress is the leading force of economic growth. For technological progress to occur not only the discovery of new technologies but also their adoption, that is, the deployment of technological advances in firms' products and production processes, is crucial.

Empirical observations (see e.g., Griliches, 1957, Mansfield, 1968 and 1985, Stoneman, 1983) indicate that new technologies are adopted by firms with delay and that they are diffused over time. A prominent example is the adoption of basic oxygen furnace (BOF) in the process of steel-making (Hoppe, 2002). Although BOF was discovered in 1949, it was not until 1964 that it was first adopted by a U.S. steel producing firm. The rest of the steel producing firms adopted BOF after 1964. Another example is the adoption of e-commerce technology in retailing. The adoption rates of e-commerce vary considerably not only among retailers of different product categories but also among retailers operating in the same product market (Dinlersoz and Pereira, 2007).

In this paper, we explore how product market competition influences firms' timing of technology adoption. We allow for product differentiation and for competition both in quantities and in prices. We compare adoption patterns obtained under alternative modes of competition as well as with those that are socially optimal.

We use a framework in which two competing firms that initially employ the same production technology consider adopting a new cost-reducing technology that has appeared in the market. If a firm adopts the technology before its rival, it will enjoy a competitive advantage. If a firm waits, it will incur lower technology adoption costs due to either economies of learning or basic research adoption process innovations. We analyze what happens both when firms can precommit to their adoption dates - precommitment game- and when firms are flexible in altering their adoption plans - preemption game.

We show that the speed of technology adoption is crucially related to and shaped by the market features, most notably by the mode of market competition. In particular, the speed of technology adoption differs not only among similar firms - i.e. there is technology diffusion in equilibrium - but also among markets with Cournot and Bertrand competition. In fact, Cournot competition leads to earlier first adoption than Bertrand competition when firms can precommit to their adoption dates and their products are sufficiently differentiated. Intuitively, under Cournot competition, technology adoption increases the adopter's own output 
and decreases its rival's output. Thus, technology adoption has a positive strategic effect that increases its attractiveness. In contrast, under Bertrand competition the strategic effect of adoption is negative since adoption decreases not only the adopter's price but also the price of its rival, diminishing thus adoption incentives. There is, however, an additional effect at play. The output effect that captures the fact that a firm has stronger adoption incentives when the cost-reduction applies to a larger production volume. The output effect is stronger under Bertrand than under Cournot competition. Competition is fiercer when it takes place in prices and as a consequence the increase in a firm's output due to adoption is more drastic in this case. When the products are differentiated enough, the output effect is insignificant and the strategic effect leads to earlier first adoption under Cournot competition. When instead the products become closer substitutes and thus the competition gets fiercer, the output effect becomes more prominent and dominates the strategic effect. Interestingly, Cournot competition encourages more than Bertrand competition the technology adoption by the second firm too. This holds independently of product substitutability and of whether or not firms can precommit to their adoptions dates. In other words, the strategic effect always dominates the output effect for the second adopter.

The above findings point out that more competition does not necessarily lead to earlier technology adoption. This conclusion is reinforced by our results regarding the role of product substitutability. We find that when firms can precommit to their adoption dates, the relationship between competition intensity, measured by product substitutability, and the first firm's adoption incentives is U-shaped. Therefore, competition, measured either as an increase in product substitutability or as a shift from Cournot to Bertrand competition, encourages technology adoption only when products are sufficiently close substitutes. Intuitively, more competition means lower pre-adoption and post-adoption profits, and thus lower adoption incentives. However, more competition also means larger competitive advantage for the firm which is the only adopter for some period of time. When the products are close substitutes, the latter positive effect of competition gets stronger. It dominates the negative effect and accelerates the first adoption. Regarding the second adoption, we find that an increase in product substitutability and thus an intensification of competition typically weakens the adoption incentives.

From a welfare perspective, our analysis shows that firms sometimes adopt the new technology too fast. This holds for the first adoption when firms cannot precommit to their adoption 
dates and the products are close substitutes. It also holds for the second adoption when the new technology is not too drastic and the products are close substitutes. In all other cases, the speed of technology adoption is too slow relative to the social optimum. Interestingly, these results are qualitatively similar under Cournot and Bertrand competition. Thus, the optimal policy towards technology adoption, subsidization or taxation, should not depend on the mode of market competition. Still, the optimal level of subsidy or tax should depend on the mode of market competition as well as on whether products are close substitutes, how drastic the new technology is and whether the adoption plans can change easily.

The analysis of firms' timing of technology adoption has attracted wide attention in the industrial organization literature (see e.g., Reinganum, 1981a\&b and 1983a\&b, Fudenberg and Tirole, 1985, Hendricks, 1992, Riordan, 1992, Gotz, 1999 and 2000, Hoppe and LehmannGrube, 2001, Ruiz-Aliseda and Zemsky, 2006). This literature has considered one market structure, typically characterized by homogenous products and competition in quantities. In such a market, Reinganum (1981a, 1983a\&b) was the first to demonstrate that a new technology is diffused over time assuming that firms can precommit to specific adoption dates (precommitment). Fudenberg and Tirole (1985), moving to the opposite extreme where firms can observe and react instantaneously to their rivals' adoptions, demonstrated that firms' profits are equalized in equilibrium since each firm adopts preemptively to prevent, or delay, adoption by its opponent (preemption). ${ }^{1}$ Considering both precommitment and preemption, we extend the literature by examining how market competition affects the timing of technology adoption and showing that the speed of technology adoption differs across markets. As pointed out by Hoppe (2002), the technology adoption literature has paid far too little attention to welfare issues and public policies. We fill this gap by performing an in depth welfare analysis that allows us to examine the circumstances under which policy intervention is desirable as well as the form that such intervention should take.

Our work is also related to the literature that explores the impact of competition on innovation. The findings of this literature are quite mixed. For instance, Qiu (1997), Symeonidis (2003) and Hinloopen and Vandekerckhove (2007), considering an oligopolistic market, have demonstrated that a shift from a more competitive market characterized by Bertrand competition to a less competitive market with Cournot competition can reinforce firms' incentives to

\footnotetext{
${ }^{1}$ Reinganum (1989) and Hoppe (2001) provide an excellent survey of this literature.
} 
invest in R\&D. Sacco (2008) and Tishler and Milstein (2009), also considering an oligopolistic market but using product substitutability as a measure of competition, have found that there is a U-shaped relationship between competition and firms' investments in cost-reducing R\&D. Aghion et al. (2006) instead, in a general equilibrium setting where competition is measured in terms of the Lerner index, have concluded that there is an inverted U-shaped relationship between competition and innovation. None of these papers has dealt with technology adoption and thus it has not examined the role of market competition on technology diffusion patterns.

The rest of the paper is organized as follows. In Section 2, we describe the model and analyze product market competition. In Section 3, the market adoption patterns under both Cournot and Bertrand competition are analyzed and compared among them. In Section 4, the socially optimal adoption pattern is derived and compared with the market adoption patterns. Section 5 includes some concluding remarks. All the proofs are relegated to the Appendix.

\section{Model Description and Product Market Competition}

We consider an economy with an imperfectly competitive sector, consisting of two firms, denoted by $i, i=1,2$, that produce differentiated goods, and a competitive numeraire sector. There is a representative consumer in the economy with the following utility:

$$
U\left(q_{i}, q_{j}\right)=a\left(q_{i}+q_{j}\right)-\frac{1}{2}\left(q_{1}^{2}+2 \gamma q_{1} q_{2}+q_{2}^{2}\right)+M, \quad i, j=1,2, \quad i \neq j, \quad 0<\gamma<1
$$

where $q_{i}$ and $q_{j}$ are respectively firm $i$ 's and firm $j$ 's output, and $M$ is the numeraire good. The parameter $\gamma$ denotes the degree of product substitutability. Namely, the higher is $\gamma$, the closer substitutes the products of the two firms are. Since the utility function is separable and linear in the numeraire good, there are no income effects and we can perform a partial equilibrium analysis. More specifically, the maximization problem of the representative consumer, $\max _{\left(q_{i}, q_{j}\right)} U\left(q_{i}, q_{j}\right)-p_{i} q_{i}-p_{j} q_{j}$, gives rise to the following demand and inverse demand functions for firm $i$ :

$$
\begin{aligned}
& q_{i}=\frac{\left(a-p_{i}\right)-\gamma\left(a-p_{j}\right)}{1-\gamma^{2}} \\
& p_{i}=a-q_{i}-\gamma q_{j} .
\end{aligned}
$$

We assume that time is continuous, denoted by $t \geq 0$, and that the horizon is infinite. Ini- 
tially, the two firms operate in the market with the same technology, facing the same marginal production $\operatorname{cost} c_{i}=c$, with $a>c>0$. A new cost-reducing technology becomes available in the market at date $t=0$. If firm $i$ adopts the new technology at $t \geq 0$ then its marginal production cost reduces from $c_{i}=c$ to $c_{i}=c-\Delta$, with $0<\Delta<c$, thereafter. As standard in the literature, we assume that no further technical advances are anticipated in the market.

The discounted cost of adopting the new technology at date $t$ is given by $k(t)$. This cost includes both the present value of the cost of purchasing the new technology and the adjustment cost of bringing the new technology on line at date $t$. The "current cost" of bringing the new technology on line by date $t$ is given by $k(t) e^{r t}$, where $r$, with $0<r<1$, is the interest rate. Following Fudenberg and Tirole (1985) and most of the subsequent literature, we assume that the current cost of adoption decreases over time at a decreasing rate, i.e., $\left(k(t) e^{r t}\right)^{\prime}<0$ and $\left(k(t) e^{r t}\right)^{\prime \prime}>0$. The decrease in the adoption cost can be due to either economies of learning or new results from basic research that facilitate the adoption process. Furthermore, we assume that $\lim _{t \rightarrow 0} k(t)=-\lim _{t \rightarrow 0} k^{\prime}(t)=\infty$ and $\lim _{t \rightarrow \infty} k^{\prime}(t) e^{r t}=0$ in order to guarantee respectively that the immediate technology adoption is prohibitively costly and that all technology adoptions occur in finite time under all parameter configurations. ${ }^{2}$

We consider two alternative technology adoption games. In the first game that originates from Reinganum (1981a\&b), each firm $i$ precommits at $t=0$ to a specific adoption date $T_{i}$, that captures the time by which its adoption will be completed. The two firms then compete in the product market, either in quantities or in prices, each period $t$ over an infinite horizon. We refer to this game as the precommitment game since it captures the idea that in order to bring the new technology on line a firm often has to make long term plans. It is important to note that precommitment at $t=0$ is a time consistent behavior only if the costs of altering the adoption plans are prohibitively high and thus the threat of altering one's adoption date as a response to the rival's past actions is not credible. An alternative justification for this game is the existence of infinitely long information lags.

In the second game, based on Fudenberg and Tirole (1985), a firm cannot credibly commit to maintain its adoption date regardless of what happened in the past. This could be so because the costs of altering adoption plans are not significant or the information lags are negligible. We refer to this game as the preemption game since as demonstrated by Fudenberg

\footnotetext{
${ }^{2}$ It should be noted that the latter assumption is not crucial for our results. It only serves to avoid the complications of corner solutions.
} 
and Tirole (1985), when firms can observe and react to their rival's actions, they have incentives for "preemptive adoption", that is, firms adopt sooner than they would adopt if their rivals' adoption dates were fixed.

In what follows, we analyze the product market competition, given firms' technology adoption decisions.

\section{Cournot Competition}

When product market competition takes place in quantities each firm $i$ chooses its quantity $q_{i}$ in order to maximize its per-period gross (from the adoption cost) profits:

$$
\underset{q_{i}}{\operatorname{Max}} \pi_{i}\left(q_{i}, q_{j}, c_{i}, c_{j}\right)=\left(a-q_{i}-\gamma q_{j}\right) q_{i}-c_{i} q_{i}
$$

This results in the per-period equilibrium firms' quantities and gross profits:

$$
q_{i}^{C}\left(c_{i}, c_{j}\right)=\frac{2\left(a-c_{i}\right)-\gamma\left(a-c_{j}\right)}{\left(4-\gamma^{2}\right)} ; \pi_{i}^{C}\left(c_{i}, c_{j}\right)=\left[q_{i}\left(c_{i}, c_{j}\right)\right]^{2}
$$

It is important to note that firm $i$ 's adoption of the cost-reducing technology increases its own quantity $q_{i}^{C}$ and decreases its rival's quantity $q_{j}^{C}$. The latter effect is strategically advantageous for firm $i$ because, as it can bee seen from (3), its own price is negatively related to firm $j$ 's quantity. Thus, under Cournot competition technology adoption has a positive strategic effect.

\section{Bertrand Competition}

When product market competition takes place in prices each firm $i$ chooses its price $p_{i}$ in order to maximize its per-period gross profits:

$$
\underset{p_{i}}{\operatorname{Max}} \pi_{i}\left(p_{i}, p_{j}, c_{i}, c_{j}\right)=\left(p_{i}-c_{i}\right) \frac{\left(a-p_{i}\right)-\gamma\left(a-p_{j}\right)}{1-\gamma^{2}}
$$

This gives rise to the per-period equilibrium firms' prices and gross profits:

$$
p_{i}^{B}\left(c_{i}, c_{j}\right)=\frac{(2+\gamma)(1-\gamma) a+2 c_{i}+\gamma c_{j}}{\left(4-\gamma^{2}\right)} ; \pi_{i}^{B}\left(c_{i}, c_{j}\right)=\frac{\left[p_{i}^{B}\left(c_{i}, c_{j}\right)-c_{i}\right]^{2}}{\left(1-\gamma^{2}\right)}
$$

Observe that when firm $i$ adopts the cost-reducing technology then both its own price $p_{i}^{B}$ and the price of its rival $p_{j}^{B}$ decrease. The latter is disadvantageous for firm $i$ since its quantity is positively related to $p_{j}$. In contrast then to Cournot competition, under Bertrand competition the strategic effect of technology adoption is negative. 
In order to avoid corner solutions, and in particular, in order to guarantee that both firms are active in the market in all the cases under consideration, we assume the following throughout the paper:

Assumption 1: $\gamma<\gamma_{B}(\delta)$, where $\gamma_{B}(\delta)=\left[-(1+\delta)+\sqrt{8+(1+\delta)^{2}}\right] / 2$, with $\delta \equiv \Delta / A$ and $A \equiv a-c$.

\section{Firms' Optimal Adoption Timing}

In this Section, we examine firms' optimal adoption dates. By convention and without loss of generality, we assume throughout that if firms adopt the new technology sequentially then firm 1 is the one that adopts it first.

\subsection{Precommitment Game}

We start by analyzing the game in which each firm $i$ can precommit at $t=0$ to its adoption date, $T_{i}^{m}$, with $m=C$ when there is Cournot competition in the market and $m=B$ when there is Bertrand competition.

At $t=0$, firm 1 and firm 2 choose $T_{1}$ and $T_{2}$ respectively in order to maximize their discounted sum of profits:

$$
\begin{aligned}
& \underset{T_{1}}{\operatorname{Max}} \Pi_{1}^{m}\left(T_{1}, T_{2}\right) \equiv \int_{0}^{T_{1}} \pi_{0}^{m} e^{-r t} d t+\int_{T_{1}}^{T_{2}} \pi_{l}^{m} e^{-r t} d t+\int_{T_{2}}^{\infty} \pi_{b}^{m} e^{-r t} d t-k\left(T_{1}\right) ; \\
& \underset{T_{2}}{\operatorname{Max}} \Pi_{2}^{m}\left(T_{1}, T_{2}\right) \equiv \int_{0}^{T_{1}} \pi_{0}^{m} e^{-r t} d t+\int_{T_{1}}^{T_{2}} \pi_{f}^{m} e^{-r t} d t+\int_{T_{2}}^{\infty} \pi_{b}^{m} e^{-r t} d t-k\left(T_{2}\right),
\end{aligned}
$$

where $\pi_{0}^{m} \equiv \pi^{m}(c, c)$ denotes firm i's per-period gross profits when none of the firms has adopted the new technology and $\pi_{b}^{m} \equiv \pi^{m}(c-\Delta, c-\Delta)$ denotes its profits when both firms have adopted the new technology. Respectively, $\pi_{l}^{m} \equiv \pi^{m}(c-\Delta, c)$ and $\pi_{f}^{m} \equiv \pi^{m}(c, c-\Delta)$ denote the per-period gross profits of the firm that has already adopted the technology - the leader - and the firm that has not yet adopted the technology - the follower.

The first order conditions of (8) and (9) are:

$$
I_{1}^{m}=-k^{\prime}\left(T_{1}^{m}\right) e^{r T_{1}^{m}} \quad \text { and } \quad I_{2}^{m}=-k^{\prime}\left(T_{2}^{m}\right) e^{r T_{2}^{m}}
$$

where $I_{i}^{m}$ denotes firm $i$ 's incremental benefits from technology adoption in market $m$, i.e., 
$I_{1}^{m} \equiv \pi_{l}^{m}-\pi_{0}^{m}$ and $I_{2}^{m} \equiv \pi_{b}^{m}-\pi_{f}^{m}$. It follows from (10) that the optimal adoption dates, $T_{1}^{m}$ and $T_{2}^{m}$, equalize firms' incremental benefits from adoption to the marginal cost of waiting.

From (5) we obtain each firm's incremental benefits under Cournot competition:

$$
\begin{aligned}
I_{1}^{C} & =\frac{4 \delta A^{2}[(2-\gamma)+\delta]}{\left(4-\gamma^{2}\right)^{2}} \\
I_{2}^{C} & =\frac{4 \delta A^{2}[(2-\gamma)+\delta(1-\gamma)]}{\left(4-\gamma^{2}\right)^{2}} .
\end{aligned}
$$

From (7) we obtain the respective incremental benefits under Bertrand competition:

$$
\begin{aligned}
I_{1}^{B} & =\frac{\delta\left(2-\gamma^{2}\right) A^{2}\left[2(1-\gamma)(2+\gamma)+\delta\left(2-\gamma^{2}\right)\right]}{\left(1-\gamma^{2}\right)\left(4-\gamma^{2}\right)^{2}} \\
I_{2}^{B} & =\frac{\delta\left(2-\gamma^{2}\right) A^{2}\left[2(1-\gamma)(2+\gamma)+\delta\left(2-\gamma^{2}-2 \gamma\right)\right]}{\left(1-\gamma^{2}\right)\left(4-\gamma^{2}\right)^{2}}
\end{aligned}
$$

Two observations are in order. First, $I_{i}^{m}>0$. That is, a firm always has incentives to adopt the new technology. Second, $I_{1}^{m}>I_{2}^{m}$. This means that the first adoption leads to more incremental benefits than the second adoption. From this and our assumptions on $k($.$) ,$ it follows immediately that in the equilibrium of the precommitment game firms' optimal adoption dates are such that $T_{1}^{m}<T_{2}^{m}$. In other words, there is technology diffusion in equilibrium. As we can see and as it was pointed out also by Quimbach (1986), the diffusion of the new technology in the market arises not from strategic behavior but rather from the declining incremental benefits of adoption and the decreasing adoption cost.

In line with the above, in order to compare firms' optimal adoption dates it is sufficient to compare their respective incremental benefits. Taking this into account, next we compare firms' adoption dates under Cournot and Bertrand competition.

Proposition 1 In the equilibrium of the precommitment game,

(i) there exists $\gamma_{1}(\delta) \equiv 2 /(2+\delta)$, with $d \gamma_{1} / d \delta<0$, such that $T_{1}^{C}<T_{1}^{B}$ if $\gamma<\gamma_{1}(\delta)$ and $T_{1}^{C}>T_{1}^{B}$ if $\gamma>\gamma_{1}(\delta)$, and

(ii) $T_{2}^{C}<T_{2}^{B}$.

According to Proposition 1(i), the new technology is adopted earlier under Cournot competition rather than under Bertrand competition when the products are relatively poor substitutes. The opposite occurs when products are close enough substitutes. The intuition is 
as follows. Technology adoption gives rise to two main effects. The first effect is the already mentioned strategic effect. Since this effect is positive under Cournot competition but negative under Bertrand competition, it reinforces the technology adoption incentives under Cournot competition and weakens them under Bertrand competition. The second effect is the output effect which refers to the fact that the higher is a firm's output the larger is its gain from adopting a cost-reducing technology (Bester and Petrakis, 1993). Since competition is more intense when it takes place in prices, the increase in a firm's output due to technology adoption is more drastic then and the output effect is stronger under Bertrand competition rather than under Cournot competition. In fact, when the products are poor substitutes their demands are hardly related and the firms' output hardly differ under the two modes of market competition. This means that the output effect is insignificant then and the strategic effect dominates. Instead, when the products are too close substitutes, technology adoption by firm 1 reduces firm 2's output to almost zero under Bertrand competition. The respective reduction in firm 2's output is much less drastic under Cournot competition. Therefore, when products are close substitutes the strategic effect is dominated by the output effect.

Regarding the second adoption, as Proposition 1(ii) states, it always takes place earlier under Cournot competition than under Bertrand competition. Clearly, this means that for the second adopter the strategic effect dominates the output effect independently of the degree of product substitutability. When the products are poor substitutes the intuition is the same as the respective one for the first adoption. When the products are close substitutes the intensity of Bertrand competition diminishes the output effect. More specifically, under Bertrand competition the post-adoption profits of the second adopter do not increase much, even if its output does increase a lot. This is due to the fierce competition between firms that are producing very similar goods. The post-adoption competition is much softer for the second adopter under Cournot competition. As a result, its profits increase sufficiently despite the fact that its output increases much less than for the second adopter under Bertrand competition.

It should be stressed that in the equilibrium of the precommitment game, not only the adoption dates of the two initially identical firms differ but also their profits differ, i.e., the discounted sum of firm 1's profits exceed the respective profits of firm 2. Thus, there is an early-mover advantage under both Cournot and Bertrand competition.

Next, we study how product differentiation influences firms' technology adoption incentives. 
Proposition 2 In the equilibrium of the precommitment game,

(i) $T_{1}^{m}$ increases in $\gamma$ if $\gamma<\gamma_{2}^{m}(\delta)$, with $d \gamma_{2}^{m} / d \delta<0$ and decreases in $\gamma$ otherwise,

(ii) $T_{2}^{B}$ always increases in $\gamma$,

(iii) $T_{2}^{C}$ increases in $\gamma$, except if $\gamma$ is large enough and $\delta$ is small enough.

It follows from Proposition 2(i) that there is an inverted U-shaped relationship between the degree of product substitutability and the optimal timing of the first adoption. This means in turn that the relationship between competition intensity, measured by product substitutability, and the investments in technology adoption is U-shaped. When goods are poor substitutes $\left(\gamma<\gamma_{2}^{m}\right)$ an increase in $\gamma$ and thus an increase in competition leads to a later first adoption. Instead, when goods are close substitutes $\left(\gamma>\gamma_{2}^{m}\right)$ and $\gamma$ increases the first adoption occurs earlier. A similar finding is included in Proposition 1(i) where we saw that a shift from Cournot to Bertrand competition, which can also be considered as an increase in competition, leads to earlier first adoption only when goods are close substitutes $\left(\gamma>\gamma_{1}\right)$ and to later adoption when they are differentiated enough $\left(\gamma<\gamma_{1}\right)$. Therefore, competition, measured either as an increase in product substitutability or as a shift from Cournot to Bertrand competition, encourages technology adoption when goods are sufficiently close substitutes. Intuitively, an increase in competition has two countervailing effects. First, more competition means lower profits, both pre-adoption and post-adoption, and thus lower adoption incentives. Second, as competition increases and only one of the firms has adopted the new technology, its ability to exploit its cost advantage by discouraging its rival's production becomes more pronounced. The second effect, which reinforces the adoption incentives, is stronger when goods are close substitutes, accelerating the adoption. When instead the goods are poor substitutes, the same positive effect is weaker and the first, negative, effect, dominates and adoption slows-down.

Regarding the second adoption, more competition measured as a shift from Cournot to Bertrand competition (Proposition 1(ii)) weakens the technology adoption incentives of firm 2. The same occurs when more competition is captured by an increase in product substitutability (Proposition 2(ii) and (iii)) unless there is Cournot competition, the new technology is nondrastic and the goods are too close substitutes. As above the negative impact of competition intensity is driven by the lower profit margin. Note that the observed exception under Cournot competition is mainly due to the fact that, for high enough $\gamma$, the leader-firm 1 adopts earlier as $\gamma$ increases (Proposition 2(i)). This latter effect is though not as strong under Bertrand 
competition and $T_{2}^{B}$ always increases with $\gamma$.

The above findings are clearly related to the literature that examines the interplay between competition and innovation. They contrast with the well known result of Aghion et al. (2006) according to which there is an inverted U-shaped relationship between competition and innovation. Aghion et al. (2006) have obtained their result in a general equilibrium setting, measuring competition in terms of the Lerner index and innovation in terms of the number of patents. More recently, Sacco (2008) and Tishler and Milstein (2009), in line with us, have provided theoretical support to the U-shaped relationship between competition measured as an increase in product substitutability and firms' investments in cost-reducing R\&D. Qiu (1997), Symeonidis (2003) and Hinloopen and Vandekerckhove (2007) also considering an oligopolistic setting have demonstrated that a shift from Cournot to Bertrand competition discourages firms' cost-reducing R\&D investments. ${ }^{3}$

\subsection{Preemption Game}

We examine now firms' optimal adoption dates when they are unable to credibly commit to their adoption dates at $t=0$. As demonstrated by Fudenberg and Tirole, in contrast to the precommitment game, both firms obtain in the preemption game the same level of discounted sum of profits in equilibrium. The intuition is straightforward. Due to the potentially higher profits for the first than for the second adopter, firm 2 has incentives to adopt the new technology just before firm 1. Firm 1, anticipating this, adopts the new technology at an earlier date such that firm 2 is indifferent between adopting just before or much after that date. In other words, the potential early-mover advantage stimulates preemption until payoffs are equalized across firms and the early-mover advantage disappears in equilibrium.

Under this setting, there is always a technology diffusion equilibrium. In this equilibrium, once firm 1 has adopted the new technology firm 2's adoption decision is a one-player decision problem. More specifically, firm 2 chooses $\tau_{2}^{m}$ in order to maximize its profits $\Pi_{2}^{m}\left(\tau_{1}, \tau_{2}\right)$ which are obtained after substituting $T_{i}$ by $\tau_{i}$ in (9). The first-order condition that arises is the same as the one in the precommitment game and is given by (10) with $\tau_{2}^{m}$ replacing $T_{2}^{m}$. This implies that firm 2 adopts the technology at the same date in the equilibrium of the preemption game and the precommitment game, i.e., $\tau_{2}^{m}=T_{2}^{m}$. In order to determine firm

\footnotetext{
${ }^{3}$ The empirical evidence on the impact of competition on innovation (see e.g., Sherer, 1967, Aghion et al., 2006, Mansfield, 1968, Kraft, 1989, Blundell et al., 1999, Geroski, 1995, Nickell, 1996) are also mixed.
} 
1's optimal adoption date, $\tau_{1}^{m}$, we use the fact that firms' profits are equalized in equilibrium, i.e., $\Pi_{1}^{m}\left(\tau_{1}^{m}, \tau_{2}^{m}\right)=\Pi_{2}^{m}\left(\tau_{1}^{m}, \tau_{2}^{m}\right)$. From (8) and (9) and after some manipulations we get:

$$
\pi_{l}^{m}-\pi_{f}^{m}=r \frac{k\left(\tau_{1}^{m}\right)-k\left(\tau_{2}^{m}\right)}{e^{-r \tau_{1}^{m}}-e^{-r \tau_{2}^{m}}}
$$

As it can be seen firm 1's optimal adoption date depends only on the difference between the per-period profits of the leader and the follower, $\pi_{l}^{m}-\pi_{f}^{m}$. Following Katz and Shapiro (1987), we refer to this difference as firm 1's per-period preemptive incentives. A comparison of the per-period preemptive incentives under Bertrand and Cournot competition is included in the next Lemma.

Lemma 1 The per-period preemptive incentives under Bertrand and Cournot competition are equal, i.e., $\pi_{l}^{C}-\pi_{f}^{C}=\pi_{l}^{B}-\pi_{f}^{B}$, and they are increasing in $\gamma$.

Interestingly, firm 1's preemptive incentives are the same under Bertrand and Cournot competition. Intuitively, there are two opposite forces in action that counterbalance each other. First, competition in prices is fiercer than competition in quantities. This means that the difference in the profits of the low-cost leader and the high-cost follower is larger under Bertrand competition and thus that the preemptive incentives of firm 1 are stronger under Bertrand competition. Second, the leader's adoption generates positive externalities for the follower under Bertrand competition, but negative externalities under Cournot competition. This means in turn that firm 1 has stronger per-period preemptive incentives under Cournot than under Bertrand competition.

Next, we compare firms' optimal adoption dates under Bertrand and Cournot competition.

Proposition 3 In the technology diffusion equilibrium of the preemption game,

(i) $\tau_{1}^{B}<\tau_{1}^{C}$, and

(ii) $\tau_{2}^{B}>\tau_{2}^{C}$.

Driven by Lemma 1 one might be tempted to claim that the mode of product market competition, Cournot or Bertrand, does not affect the preemptive incentives. However, according to Proposition 3(i), firm 1's overall incentives to preempt are stronger under Bertrand than under Cournot competition. In fact, the first adopter enjoys the leadership longer under Bertrand competition than under Cournot competition since the second adoption, just like in 
the precommitment game, takes place later under Bertrand competition (Proposition 3(ii)). The intuition is as follows. Since firm's per-period preemptive incentives are the same under Bertrand and Cournot competition, the profit differential of the leader and the follower is also the same for the same adoption dates, $\Pi_{l}^{B}\left(\tau_{1}, \tau_{2}\right)-\Pi_{f}^{B}\left(\tau_{1}, \tau_{2}\right)=\Pi_{l}^{C}\left(\tau_{1}, \tau_{2}\right)-\Pi_{f}^{C}\left(\tau_{1}, \tau_{2}\right)$. As $\tau_{2}$ increases, i.e., as the follower adopts the technology later, the leader enjoys the competitive advantage longer and as a consequence the profit differential increases. Since $\tau_{2}^{B}>\tau_{2}^{C}$, it follows that the profit differential would be larger under Bertrand than under Cournot competition as long as $\tau_{1}^{B}=\tau_{1}^{C}$. On the other hand, as $\tau_{1}^{m}$ increases, the profit differential increases because the leader saves on adoption costs. Therefore, for profit equalization to occur in equilibrium, the leader should adopt later in the Cournot than in the Bertrand competition, i.e., $\tau_{1}^{B}<\tau_{1}^{C}$.

Proposition 4 below includes our findings regarding the impact of product differentiation on firm 1's adoption dates.

Proposition 4 In the technology diffusion equilibrium of the preemption game,

(i) $\tau_{1}^{B}$ decreases in $\gamma$,

(ii) $\tau_{1}^{C}$ decreases in $\gamma$ when $\delta$ is sufficiently high as well as when $\gamma$ is sufficiently low.

Combining Propositions 3(i) and 4(i) we conclude that in the preemption game, more competition, measured either as a shift from Cournot to Bertrand competition or as an increase in $\gamma$, leads to earlier adoption for firm 1 and thus to stronger technology adoption incentives. ${ }^{4}$ An increase in the intensity of competition, exerts more pressure on the leader to exploit its cost advantage before the follower does so and thus the leader accelerates adoption. This is similar to our result in the precommitment game with goods that are close substitutes. In contrast, from Proposition 2(ii) and (iii) that holds here too and Proposition 3(ii), we see that competition affects negatively firm 2's technology adoption incentives.

We should stress that under certain conditions the above described technology diffusion equilibrium is not the unique equilibrium of the preemption game. As demonstrated by Fudenberg and Tirole (1980), there could be an another equilibrium too: a joint adoption equilibrium, in which both firms adopt the new technology at the same date, $\tau_{1}^{m}=\tau_{2}^{m}=\tau_{J}^{m}$. The exact conditions for its existence are analytically intractable. Still, setting $k(t)=e^{-(\alpha+r) t}$, with

\footnotetext{
${ }^{4}$ Our numerical simulations indicate that Proposition 4(ii) holds also for $\gamma$ high enough and $\delta$ low enough.
} 
$\alpha>0$, and using numerical simulations we observe that under both Cournot and Bertrand competition a necessary condition for the existence of a joint adoption equilibrium is that the new technology is not too drastic. More specifically, when $\delta$ is low enough then a joint adoption equilibrium always exists, while when $\delta$ takes intermediate values a joint adoption equilibrium exists only if the goods are sufficiently differentiated $(\gamma$ low). This occurs because when the new technology is not too drastic ( $\delta$ low), the best reaction to early adoption is to quickly follow suit. Since the rival will follow soon, the gains from preemption are low and thus firm 1's incentives to adopt before firm 2 are weak. Firm 1 then prefers to wait and adopt the new technology much later, and simultaneously with firm 2 , in order to save on adoption costs and enjoy higher profits. In fact, at the optimal joint adoption date, industry profits are maximized and shared equally between firms, such that each firm obtains profits higher than the leader's profits in the precommitment game. The following Proposition summarizes our results.

Proposition 5 In the joint adoption equilibrium of the preemption game,

(i) $\tau_{J}^{C}<\tau_{J}^{B}$, and

(ii) $\tau_{J}^{m}>\tau_{2}^{m}=T_{2}^{m}$.

When firms adopt the technology at the same date, this date is earlier under Cournot than under Bertrand competition (Proposition 5(i)). This is so because industry profits are higher under Cournot rather than under Bertrand competition and thus joint adoption incentives are stronger in the former than in the latter case. Clearly, the optimal joint adoption date is later than the second adoption date in the technology diffusion equilibrium of both the preemption and the precommitment game (Proposition 5(ii)). This is so because $\pi_{b}^{m}-\pi_{0}^{m}<\pi_{b}^{m}-\pi_{f}^{m}$, i.e. the follower's incentives to adopt the new technology are stronger than each firm's incentives when both adopt at the same date. Therefore, late joint adoption maximizes industry's profits.

\section{Socially-Optimal Adoption Timing}

In this Section, we investigate the optimal technology adoption pattern from a welfare viewpoint and compare it with the adoption patterns that prevail in the market equilibrium. We define the per-period gross welfare $V$ as the sum of consumers' and producers' surplus. We assume that the social planner is unable to influence firms' behavior in the product market (i.e., their price or quantity choices). Thus, we focus throughout on second-best socially optimal 
adoption patterns.

The social planner, taking the market structure as given, chooses the adoption dates so as to maximize social welfare:

$$
\underset{T_{1}, T_{2}}{\operatorname{Max}} W^{m}\left(T_{1}, T_{2}\right)=\int_{0}^{T_{1}} V_{0}^{m} e^{-r t} d t+\int_{T_{1}}^{T_{2}} V_{1}^{m} e^{-r t} d t+\int_{T_{2}}^{\infty} V_{b}^{m} e^{-r t} d t-k\left(T_{1}\right)-k\left(T_{2}\right),
$$

where $V_{0}^{m} \equiv V^{m}(c, c), V_{1}^{m} \equiv V^{m}(c-\Delta, c)$, and $V_{b}^{m} \equiv V^{m}(c-\Delta, c-\Delta)$ are respectively the per-period gross welfare if none, only one, or both firms have adopted the new technology in market $m$, and

$$
V^{m}\left(c_{1}, c_{2}\right) \equiv U\left(q_{1}^{m}\left(c_{1}, c_{2}\right), q_{2}^{m}\left(c_{1}, c_{2}\right)\right)-c_{1} q_{1}^{m}\left(c_{1}, c_{2}\right)-c_{2} q_{2}^{m}\left(c_{1}, c_{2}\right)
$$

The first order conditions of (16) are:

$$
V_{1}^{m}-V_{0}^{m}=-k^{\prime}\left(T_{1}^{S m}\right) e^{r T_{1}^{S m}} \quad \text { and } \quad V_{b}^{m}-V_{1}^{m}=-k^{\prime}\left(T_{2}^{S m}\right) e^{r T_{2}^{S m}}
$$

Let $I_{1}^{S m} \equiv V_{1}^{m}-V_{0}^{m}$ and $I_{2}^{S m} \equiv V_{b}^{m}-V_{1}^{m}$ be the social planner's incremental benefits from firm 1's and firm 2's technology adoption respectively.

Substituting (5) into (17) and (18), we obtain the incremental social benefits under Cournot competition:

$$
\begin{aligned}
I_{1}^{S C} & =\frac{\delta A^{2}\left[2(3+\gamma)(2-\gamma)^{2}+\delta\left(12-\gamma^{2}\right)\right]}{2\left(4-\gamma^{2}\right)^{2}} \\
I_{2}^{S C} & =\frac{\delta A^{2}\left[2(3+\gamma)(2-\gamma)^{2}+\delta\left(12-\gamma^{2}-16 \gamma+2 \gamma^{3}\right)\right]}{2\left(4-\gamma^{2}\right)^{2}}
\end{aligned}
$$

Further, substituting (7) into (2) and using (17) and (18), we obtain the respective benefits under Bertrand competition:

$$
\begin{aligned}
I_{1}^{S B} & =\frac{\delta A^{2}\left[2(3-2 \gamma)(1-\gamma)(2+\gamma)^{2}+\delta\left(12-9 \gamma^{2}+2 \gamma^{4}\right)\right]}{2\left(1-\gamma^{2}\right)\left(4-\gamma^{2}\right)^{2}} \\
I_{2}^{S B} & =\frac{\delta A^{2}\left[2(3-2 \gamma)(1-\gamma)(2+\gamma)^{2}+\delta\left(12-16 \gamma-9 \gamma^{2}+6 \gamma^{3}+2 \gamma^{4}\right)\right]}{2\left(1-\gamma^{2}\right)\left(4-\gamma^{2}\right)^{2}}
\end{aligned}
$$

It follows from the above that $I_{i}^{S m}>0$ and $I_{1}^{S m}>I_{2}^{S m}$. Moreover, from (18), we see that that $T_{i}^{S m}$ depends only on $I_{i}^{S m}$. Given all these and the fact that $\left[-k^{\prime}(t) e^{r t}\right]$ is decreasing in $t$, 
it follows that the socially optimal adoption dates, $T_{1}^{S m}$ and $T_{2}^{S m}$, are such that $T_{1}^{S m}<T_{2}^{S m}$. In other words, technology diffusion is socially optimal.

We turn now to the comparison of the socially optimal adoption pattern with the one that arises in the market when firms can precommit to their adoption dates.

Proposition 6 In the precommitment game,

(i) $T_{1}^{S m}<T_{1}^{m}$

(ii) when $\delta>0.781$ then $T_{2}^{S m}<T_{2}^{m}$

(iii) when $\delta<0.781$ then there exists $\gamma_{3}(\delta) \equiv(2+\delta) / 2(1+\delta)$, with $d \gamma_{3} / d \delta<0$, such that $T_{2}^{S m}<T_{2}^{m}$ if $\gamma<\gamma_{3}(\delta)$ and $T_{2}^{S m}>T_{2}^{m}$ otherwise. .

Proposition 6(i) states that firm 1 always adopts the new technology too late in comparison with the socially optimal adoption date. The reason is that firm 1 cannot appropriate the full social surplus generated by the adoption in the market, so it prefers to wait a little longer when the costs of bringing the new technology on line become lower. This finding is related to Dasgupta and Stiglitz's (1980) observation that non-appropriability of social surplus leads to underinvestment relative to the social optimum. A similar reasoning applies for firm 2 too whenever the new technology is drastic in cost reduction $(\delta>0.781)$. As Proposition 6(ii) states firm 2 adopts too late as compared with the optimal adoption date in this case too.

Nevertheless, when the new technology is not too drastic $(\delta<0.781)$, whether or not firm 2 adopts the technology earlier or later than it is socially optimal depends on product substitutability. According to Proposition 6(iii), if the goods are sufficiently close substitutes, firm 2 adopts the new technology earlier in the market (Cournot or Bertrand) than in the social optimum. ${ }^{5}$ The reverse, however, is true if the goods are poor substitutes. The intuition is as follows. When goods are very poor substitutes, firm 2 is almost a monopolist in the market and thus it cannot appropriate the full social surplus generated by the cost-reducing innovation. As a consequence, it waits relatively longer for the costs of bringing the innovation on line to decrease sufficiently to compensate for the part of social surplus which it cannot appropriate. However, if products are too close substitutes then firm 2 produces a tiny share before adoption. Given that almost all production is already done by firm 1 with the low cost technology, and that the goods are close substitutes, the adoption of the innovation by firm 2 increases the

${ }^{5}$ This condition is satisfied whenever, given $\Delta$, the market is not too small. 
social surplus only by little. This is so because the cost-reducing technology applies only to firm 2's tiny production share. On the other hand, innovation increases significantly firm 2's share in the market, thus creating a strong incentive to adopt the new technology earlier. This business-stealing effect dominates the non-appropriability effect when goods are sufficiently close substitutes and so firm 2 in the market adopts earlier than in the second-best optimum.

One might wonder how Cournot and Bertrand adoption patterns compare among themselves in terms of social welfare. Numerical simulations indicate that Bertrand competition is always preferable from a welfare point of view although as we saw in Section 3, the incentives for technology adoption are sometimes stronger under Cournot competition. ${ }^{6}$

Next we compare the socially optimal adoption pattern with the firm's optimal adoption pattern in the preemption game. We know from Subsection 3.2 that the per-period preemptive incentives of firm 1 are given by $\pi_{l}^{m}-\pi_{f}^{m}$ and that they increase as the goods become closer substitutes. Furthermore, from Proposition 2 we know that $T_{2}^{m}$ is typically increasing in $\gamma$ under both Bertrand and Cournot competition, i.e., the closer substitutes the two goods are, the later firm 2 adopts the new technology in the market. It can also be checked from (19) and (21) that $\partial I_{1}^{S m} / \partial \gamma<0$ except if $\gamma$ is too high, $m=B, C$. Thus as the goods become closer substitutes the social planner typically postpones adoption. All these lead us to the following conjecture: Firm 1 adopts the technology earlier in the technology diffusion equilibrium of the preemptiom game than in the second-best optimum, i.e., $\tau_{1}^{C}<T_{1}^{S C}$, when the goods are sufficiently close substitutes. Setting $k(t)=e^{-(\alpha+r) t}$ and using numerical simulations, we confirm that this is indeed the case.

Regarding the date of the second adoption as it was pointed out in Subsection 3.2 firm 2 adopts the technology in the technology diffusion equilibrium of preemption game at the same date as in the precommitment game. Thus, Proposition 6(ii) and (iii) holds here too. Similarly also to the precommitment game numerical simulations indicate that in the technology diffusion equilibrium of the preemption game welfare is always higher under Bertrand than under Cournot competition.

Turning to the comparison of the socially optimal adoption pattern with the firms' optimal adoption pattern in the other possible type of equilibrium in the preemption game, the joint adoption equilibrium, we find that when the new technology is not too drastic $(\delta<0.781)$

\footnotetext{
${ }^{6}$ Numerical simulations are available from the authors upon request.
} 
the market leads to a later adoption than it is socially-optimal, $T_{2}^{S m}<\tau_{J}^{m}$. This is not very surprising since as we saw in the discussion of Proposition 5, the new technology is adopted quite late when firm 1 forsakes its incentive to preempt firm 2.

Regarding policy implications, it follows from the above discussion that when firms can precommit to their adoption dates then the subsidization of firm 1's adoption is a welfareimproving policy regardless of the mode of market competition. When instead firms are unable to precommit and their products are close substitutes the optimal policy, both under Bertrand and Cournot competition, is to tax the first adopter. The optimal policy towards firm 2's adoption, subsidization or taxation, is also the same under both modes of market competition. Surprisingly then the qualitative features of the comparison between the social optimal and the market adoption patterns are similar under Cournot and Bertrand competition despite the fact that technology adoption creates a positive strategic effect in Cournot and a negative strategic effect in Bertrand competition. Yet, the optimal adoption level of subsidy or tax depends on the mode of market competition as well as on a number of other market characteristics such as product substitutability $\gamma$ and the relative effectiveness of the new technology $\delta$.

\section{Concluding Remarks}

In this paper, we have explored the impact of market competition on firms' incentives to adopt a cost-reducing technology. We have also compared the private and the public incentives for technology adoption.

We have found that differences in market structures, in terms of product substitutability or mode of competition, generate significant differences in firms' technology adoption patterns. In particular, the latter differ not only among symmetric firms (i.e., there is technology diffusion), but most importantly among markets with Cournot and Bertrand competition and with different degrees of product substitutability. We have also found that an increase in competition, captured either by a shift from Cournot to Bertrand competition or by an increase in product substitutability, can discourage technology adoption. This holds always for the firm that adopts the technology second. It also holds for the firm that adopts the technology first as long as firms can precommit to their adoption dates and their products are sufficiently differentiated. Our findings point out that the relationship between competition toughness and adoption incentives is not always monotonic. Moreover, they give rise to a number of testable 
implications regarding the role that the distinct market features play in determining the timing of technology adoption.

Comparing the market adoption pattern with the socially optimal one, we have provided a number of insights for the design of technology policy aiming at correcting the market inefficiencies. We have found that whether a social planner should tax or subsidize technology adoption depends crucially on firms' flexibility to alter their adoption plans as well as on product substitutability. The mode of competition, Bertrand or Cournot, should not affect qualitatively the appropriate policy measures. However, it should be taken into account along with other market features, such as the effectiveness of the new technology, while choosing the optimal level of the tax or subsidy applied.

This paper has improved our understanding on how product market competition influences the private and public incentives to adopt a new technology. Yet, it has done so without considering a number of other factors, such as the uncertainty about the new technology's effectiveness, the length of time required for its successful implementation (Reinganum, 1983a\&b, Stenbacka and Tombak, 1994) and the possibilities of imitation and licensing (Katz and Shapiro, 1987). Introducing one or more of these factors into our framework will provide further insights into the design of the technology policy, a task left for future research.

\section{Appendix}

\section{Proof of Proposition 1}

(i) From (11) and (13), it follows that $I_{1}^{C}>I_{1}^{B}$ if and only if $\left[((2-\gamma)-\gamma(1+\delta)) \delta \gamma^{3} /(1-\right.$ $\left.\left.\gamma^{2}\right)\left(4-\gamma^{2}\right)^{2}\right]>0$, or equivalently if and only if $[(1 /(1+\delta))>(\gamma /(2-\gamma))]$. The latter is true if and only if $\gamma<\gamma_{1}(\delta) \equiv 2 /(2+\delta)$. It can be checked that $\gamma_{1}(\delta)<\gamma_{B}(\delta)$ for all $\delta$. Clearly, $\frac{\partial \gamma_{1}}{\partial \delta}<0$

(ii) From (12) and (14), it follows that $I_{2}^{C}>I_{2}^{B}$ if and only if $\left[(2(1-\gamma)+(2-\gamma) \delta) \delta \gamma^{3} /(1-\right.$ $\left.\left.\gamma^{2}\right)\left(4-\gamma^{2}\right)^{2}\right]>0$. The latter is always true since both its numerator and denominator are positive.

\section{Proof of Proposition 2}

(i) Differentiating (11) in terms of $\gamma, \frac{\partial I_{1}^{C}}{\partial \gamma}$, setting the derivative equal to 0 and solving for $\gamma$, we find:

$$
\gamma_{2}^{C}(\delta)=\frac{2\left[2+\delta-\sqrt{1+4 \delta+\delta^{2}}\right]}{3},
$$


such that $\frac{\partial I_{1}^{C}}{\partial \gamma}>0$ if $\gamma>\gamma_{2}^{C}(\delta)$ and $\frac{\partial I_{1}^{C}}{\partial \gamma}<0$ if $\gamma<\gamma_{2}^{C}(\delta)$. It can be checked that $\gamma_{2}^{C}(\delta)<\gamma_{B}(\delta)$ for all $\delta$. Therefore, $\frac{\partial T_{1}^{C}}{\partial \gamma}<0$ if $\gamma>\gamma_{2}^{C}(\delta)$ and $\frac{\partial T_{1}^{C}}{\partial \gamma} \geq 0$ otherwise. Moreover, it can be checked that $\frac{\partial \gamma_{2}^{C}}{\partial \delta}<0$.

Similarly, solving $\frac{\partial I_{1}^{B}}{\partial \gamma}=0$, we see that there exists $\gamma_{2}^{B}(\delta)^{7}$, such that $\frac{\partial I_{1}^{B}}{\partial \gamma}>0$ if $\gamma>\gamma_{2}^{B}(\delta)$ and $\frac{\partial I_{1}^{B}}{\partial \gamma}<0$ if $\gamma<\gamma_{2}^{B}(\delta)$. It can be checked that $\gamma_{2}^{B}(\delta)<\gamma_{B}(\delta)$ for all $\delta$. Therefore, $\frac{\partial T_{1}^{B}}{\partial \gamma}<0$ if $\gamma>\gamma_{2}^{B}(\delta)$ and $\frac{\partial T_{1}^{B}}{\partial \gamma} \geq 0$ otherwise.

(ii) Differentiating (12) in terms of $\gamma$, it can be checked that $\frac{\partial I_{2}^{B}}{\partial \gamma}<0$ for all permissible $\gamma$ and $\delta$. Thus, $\frac{\partial T_{2}^{B}}{\partial \gamma}>0$.

(iii) Solving $\frac{\partial I_{2}^{C}}{\partial \gamma}=0$ in terms of $\gamma$, we find:

$$
\widehat{\gamma}_{2}^{C}(\delta)=\frac{2\left[2+\delta-\sqrt{1-2 \delta-2 \delta^{2}}\right]}{3(1+\delta)}
$$

where $\widehat{\gamma}_{2}^{C}(0)=0.667$ and $d \widehat{\gamma}_{2}^{C} / d \delta>0$. It can be checked that $\widehat{\gamma}_{2}^{C}(\delta)<\gamma_{B}(\delta)$ only if $\delta<$ 0.281. Therefore, for all $\delta>0.281, \frac{\partial I_{2}^{C}}{\partial \gamma}<0$ and thus $\frac{\partial T_{2}^{C}}{\partial \gamma}>0$. On the other hand, if $\delta<0.281$ then $\frac{\partial I_{2}^{C}}{\partial \gamma}>0$ if $\gamma>\widehat{\gamma}_{2}^{C}(\delta)$ and $\frac{\partial I_{2}^{C}}{\partial \gamma}<0$ if $\gamma<\widehat{\gamma}_{2}^{C}(\delta)$. Thus, $\frac{\partial T_{2}^{C}}{\partial \gamma}<0$ if $\gamma>\widehat{\gamma}_{2}^{C}(\delta)$ and $\frac{\partial T_{2}^{C}}{\partial \gamma}>0$ if $\gamma<\widehat{\gamma}_{2}^{C}(\delta)$. The above imply that $\frac{\partial T_{2}^{C}}{\partial \gamma}<0$ only if $\delta<0.281$ and $\gamma>0.667$.

\section{Lemma 1}

Using (5), and (7), we have:

$$
\pi_{l}^{C}-\pi_{f}^{C}=\frac{\delta A^{2}(2+\delta)}{\left(4-\gamma^{2}\right)}=\pi_{l}^{B}-\pi_{f}^{B}
$$

which is increasing in $\gamma$ and $\delta$.

\section{Proof of Proposition 3}

(i) Let:

$$
f\left(t_{1}, t_{2}\right)=r \frac{k\left(t_{1}\right)-k\left(t_{2}\right)}{e^{-r t_{1}}-e^{-r t_{2}}} \quad \text { and } \quad g(t)=k(t) e^{r t}
$$

By assumption $g(t)$ is strictly decreasing and strictly convex. Differentiating $f\left(t_{1}, t_{2}\right)$, we have:

$$
\frac{\partial f\left(t_{1}, t_{2}\right)}{\partial t_{1}}=r \frac{e^{-r\left(t_{1}+t_{2}\right)}\left[g^{\prime}(t)\left(e^{r\left(t_{2}-t_{1}\right)}-1\right)+r\left(g\left(t_{1}\right)-g\left(t_{2}\right)\right)\right]}{\left(e^{-r t_{1}}-e^{-r t_{2}}\right)^{2}} .
$$

By the strict convexity of $e^{x}$, we have $e^{r\left(t_{2}-t_{1}\right)}-1>r\left(t_{2}-t_{1}\right)$. Moreover, since $g(t)$ is

\footnotetext{
${ }^{7}$ Defined by $\left(\gamma_{2}^{B}\right)^{-1}(\delta)=\frac{(1-\gamma)^{2}\left(8-6 \gamma^{2}+4 \gamma^{3}+7 \gamma^{4}+2 \gamma^{5}\right)}{\gamma\left(8-8 \gamma^{2}+4 \gamma^{4}-\gamma^{6}\right)}$. It can be checked that $\frac{\partial \gamma_{2}^{B}}{\partial \delta}<0$.
} 
strictly decreasing and strictly convex, the right hand side of (24) in square brackets $[\ldots]<$ $r\left[g /\left(t_{1}\right)\left(t_{2}-t_{1}\right)+g\left(t_{1}\right)-g\left(t_{2}\right)\right]<0$. Thus, $f\left(t_{1}, t_{2}\right)$ is decreasing in $t_{1}$ and in $t_{2}$ by the symmetry of (23). Hence, $\tau_{2}^{B}>\tau_{2}^{C}$ implies $f\left(t_{1}, \tau_{2}^{B}\right)<f\left(t_{1}, \tau_{2}^{C}\right)$. Then, from (15) and Lemma 1 , it follows immediately that $\tau_{1}^{B}<\tau_{1}^{C}$.

(ii) Since $\tau_{2}^{m}=T_{2}^{m}, m=B, C$, this is straightforward from Proposition 1(ii).

\section{Proof of Proposition 4}

(i) From (15) we know that $\pi_{l}^{m}-\pi_{f}^{m}=f\left(t_{1}, t_{2}\right)=r \frac{k\left(t_{1}\right)-k\left(t_{2}\right)}{e^{-r t_{1}}-e^{-r t_{2}}}$, with $\frac{\partial f}{\partial t_{i}}<0, i=1,2$ (see Proposition 3(i)). Taking the total differential of $\pi_{l}^{m}-\pi_{f}^{m}$ we have:

$$
\frac{\partial\left(\pi_{l}^{m}-\pi_{f}^{m}\right)}{\partial \gamma} d \gamma=\frac{\partial f}{\partial t_{1}} d t_{1}+\frac{\partial f}{\partial t_{2}} d t_{2}
$$

where $d t_{2}=\frac{\partial t_{2}}{\partial \gamma} d \gamma$. Rewriting the above we have:

$$
\frac{d t_{1}}{d \gamma}=\frac{\frac{\partial\left(\pi_{l}-\pi_{f}\right)}{\partial \gamma}-\frac{\partial f}{\partial t_{2}} \frac{\partial t_{2}}{\partial \gamma}}{\frac{\partial f}{\partial t_{1}}}
$$

We know from Lemma 1 that $\frac{\partial\left(\pi_{l}^{m}-\pi_{f}^{m}\right)}{\partial \gamma}>0$. We also know from Proposition 2(ii) that under Bertrand competition that $T_{2}^{B}$ is always increasing in $\gamma$; that is, $\frac{\partial t_{2}}{\partial \gamma}>0$ for all $\gamma$ and $\delta$. Thus, the numerator of the right-hand side of $(25)$ is positive. Since its denominator is negative, it follows that $\frac{d t_{1}}{d \gamma}<0$ for all permissible $\gamma$ and $\delta$, i.e. $\tau_{1}^{B}$ is decreasing in $\gamma$.

(ii) Under Cournot competition, we know from Proposition 2(iii) that $T_{2}^{C}$ is increasing in $\gamma$ except if $\gamma$ is sufficiently large and $\delta$ is sufficiently small; that is, $\frac{\partial t_{2}}{\partial \gamma}>0$ under these conditions. It follows that sufficient conditions for the numerator of the right-hand side of (25) to be positive is that either $\delta>0.281$ or $\gamma<\widehat{\gamma}_{2}^{C}(\delta)$ for $\delta<0.281$. Under these parameter values, and since the denominator is negative, it is necessarily true that $\frac{d t_{1}}{d \gamma}<0$, i.e. $\tau_{1}^{C}$ is decreasing in $\gamma$. For the rest of the parameter values, our simulations indicate that it is still true that $\tau_{1}^{C}$ is decreasing in $\gamma$.

\section{Proof of Proposition 5}

(i) The incremental benefits in the joint adoption equilibrium are, $I_{J}^{m}=\pi_{b}^{m}-\pi_{0}^{m}$. After substituting (5) into $I_{J}^{m}$, it follows that the incremental benefits under Cournot competition are:

$$
I_{J}^{C}=A^{2} \frac{\delta(2+\delta)}{(2+\gamma)^{2}}
$$


Similarly, substituting (7) into $I_{J}^{m}$, we obtain the incremental benefits under Bertrand competition:

$$
I_{J}^{B}=A^{2} \frac{\delta(2+\delta)(1-\gamma)}{(2-\gamma)^{2}(1+\gamma)}
$$

Taking their difference, we have:

$$
I_{J}^{C}-I_{J}^{B}=A^{2} \frac{\delta(2+\delta) 2 \gamma^{3}}{\left(4-\gamma^{2}\right)^{2}(1+\gamma)}>0
$$

Thus, $I_{J}^{C}>I_{J}^{B}$. This implies in turn that $\tau_{J}^{C}<\tau_{J}^{B}$.

(ii) We know that $T_{2}^{m}$ is defined by $I_{2}^{m} \equiv \pi_{b}^{m}-\pi_{f}^{m}=-k^{\prime}\left(T_{2}^{m}\right) e^{r T_{2}^{m}}$. Respectively, $\tau_{J}^{m}$ is defined by $I_{J}^{m} \equiv \pi_{b}^{m}-\pi_{0}^{m}=-k^{\prime}\left(\tau_{J}^{m}\right) e^{r \tau_{J}^{m}}$. We also know that $\pi_{b}^{m}<\pi_{0}^{m}$. Thus, $I_{J}^{m}<I_{2}^{m}$. This means in turn that $\tau_{J}^{m}>T_{2}^{m}$.

\section{Proof of Proposition 6}

(i) From (11) and (19), we have that $I_{1}^{S C}>I_{1}^{C}$ if and only if $\left[(2(1-\gamma)+\delta) / 2\left(4-\gamma^{2}\right)\right]>0$. This is true for all $\gamma$ and $\delta$. Also, from (13) and (21), we have that $I_{1}^{S B}>I_{1}^{B}$ if and only if $\left[(2(1-\gamma)+\delta) / 2\left(4-\gamma^{2}\right)\left(1-\gamma^{2}\right)\right]>0$, which is again always true. Then, from (10) and (18) and our assumption that $-k^{\prime}(t) e^{-r t}$ is decreasing in $t$, it follows that $T_{1}^{S C}<T_{1}^{C}$ and $T_{1}^{S B}<T_{1}^{B}$. (ii) - (iii) From (12) and (20), $I_{2}^{S C}>I_{2}^{C}$ if and only if $\left[(1+(1-2 \gamma)(1+\delta)) / 2\left(4-\gamma^{2}\right)\right]>0$, which is true for $\gamma<\gamma_{3}(\delta) \equiv \frac{2+\delta}{2(1+\delta)}$. Also, from (14) and (22), we have that $I_{2}^{S B}>I_{2}^{B}$ if and only if $\left[\left(1+(1-2 \gamma)(1+\delta) / 2\left(4-\gamma^{2}\right)\left(1-\gamma^{2}\right)\right]>0\right.$, which is again always true for $\gamma<\gamma_{3}(\delta)$. It can be checked that $\gamma_{3}(\delta)<\gamma_{B}(\delta)$ only if $\delta<0.781$. Hence, $I_{2}^{S m}>I_{2}^{m}$ for all $\delta>0.781$. Then, from (10) and (18) and our assumption that $-k^{\prime}(t) e^{-r t}$ is decreasing in $t$, it follows that $T_{2}^{S m}<T_{2}^{m}$ for all $\delta>0.781$. On the other hand, if $\delta<0.781$, then $T_{2}^{S m}>T_{2}^{m}$ for all $\gamma>\gamma_{3}(\delta)$ and $T_{2}^{S m}<T_{2}^{m}$ for all $\gamma<\gamma_{3}(\delta)$.

\section{References}

Aghion, P., N. Bloom, R. Blundell, R. Griffith, and P. Howitt (2005), "Competition and Innovation: An Inverted-U Relationship," The Quarterly Journal of Economics, 120, 701-728.

Bester, H. and E. Petrakis (1993), "The Incentives for Cost Reduction in a Differentiated Industry," International Journal of Industrial Organization, 11, 519-534. 
Blundell, R., R. Griffith, and J. Van Reenen (1999), "Market Share, Market Value and Innovation in A Panel of British Manufacturing Firms," Review of Economic Studies, 66, 529-554.

Cheng, L. (1985), "Comparing Bertrand and Cournot Equilibria: A Geometric Approach," Rand Journal of Economics, 16, 146-155.

Dasgupta, P. and J. Stiglitz (1980), "Uncertainty, Industrial Structure and Speed of R\&D," The Bell Journal of Economics, 90, 1-28.

Dinlersoz, E. and P. Pereira (2007), "On the Diffusion of Electronic Commerce," International Journal of Industrial Organization, 25, 541-574.

Dixit, A. (1979), "A Model of Duopoly Suggesting a Theory of Entry Barriers", The Bell Journal of Economics, 10, 20-32.

Dutta, P. K., S. Lach, and A. Rustichini (1995), "Better Late Than Early: Vertical Differentiation in the Adoption of a New Technology," Journal od Economics and Management Strategy, 4, 563-589.

Fudenberg, D. and J. Tirole (1985), "Preemption and Rent Equalization in the Adoption of New Technology," Review of Economic Studies, 52, 383-401.

Geroski, P. (1995), Market Structure, Corporate Performance and Innovative Activity, Oxford University Press.

Götz, G. (2000), "Strategic Timing of Adoption of New Technologies under Uncertainty: A Note," International Journal of Industrial Organization, 18, 369-379.

Hinloopen, J. and J. Vandekerckhove (2007), "Dynamic Efficiency of Product Market Competition: Cournot versus Bertrand," Tinbergen Institute Discussion Paper TI 2007-097/1.

Gotz, G. (1999), "Monopolistic Competition and the Diffusion of New Technology," Rand Journal of Economics, 30, 679-693.

Gotz, G. (2000), "Strategic Timing of Adoption of New Technologies Under Uncertainty: A note", International Journal of Industrial Organization, 18, 369-379. 
Griliches, Z. (1957), "Hybrid Corn: An Exploration in the Economics of Technological Change," Econometrica, 25, 501-522.

Hendricks, K. (1992), "Reputation in the Adoption of a New Technology," International Journal of Industrial Organization, 10, 663-677.

Hoppe, H. (2002), "The Timing of New Technology Adoption: Theoretical Models and Empirical Evidence," The Manchester School, 70, 56-76.

Hoppe, H. and U. Lehmann-Grube (2001), "Second-mover Advantages in Dynamic Quality Competition," Journal od Economics and Management Strategy, 10, 419-433.

Katz, M. and C. Shapiro (1987), "R\&D Rivalry with Licensing or Imitation," American Economic Review, 77, 402-420.

Kraft, K. (1989), "Market Structure, Firm Characteristics and Innovative Activity," The Journal of Industrial Economics, 37, 329-336.

Lin, P. and K. Saggi (2002), "Product Differentiation, Process R\&D, and the Nature of Market Competition," European Economic Review, 46, 201-211.

Mansfield, E. (1961), "Technical Change and the Rate of Immitation," Econometrica, 29, 741-766.

Mansfield, E. (1968), Industrial Research and Technological Innovation: An Econometric Analysis, Longman, London.

Mansfield, E. (1985), "How Rapidly Does New Industrial Technology Leak Out?" Journal of Industrial Economics, 34, 217-223.

Nickell, S. (1996), "Competition and Corporate Performance," Journal of Political Economy,104, 724-746.

Petrakis, E. (1994), "Technology Diffusion in a Differentiated Oligopoly," Department of Economics, Universidad Carlos III de Madrid Working Paper 94-33.

Qiu, L. D. (1997), "On the Dynamic Efficiency of Bertrand and Cournot Equilibria," Journal of Economic Theory, 75, 215-229. 
Quirmbach, H. (1986), "The Diffusion of New Technology and the Market for an Innovation," Rand Journal of Economics, 17, 33-47.

Reinganum, J. (1981a), "On the Diffusion of New Technology: A Game Theoretic Approach," Review of Economic Studies, 48, 395-405.

Reinganum, J. (1981b), "Market Structure and the Diffusion of New Technology," The Bell Journal of Economics, 12, 618-624.

Reinganum, J. (1983a), "Technology Adoption under Imperfect Information," The Bell Journal of Economics, 14, 57-69.

Reinganum, J. (1983b), "Uncertain Innovation and the Persistence of Monopoly," American Economic Review, 73, 741-748.

Reinganum, J. (1989), "The Timing of Innovation: Research, Development, and Diffusion," Handbook of Industrial Organization, Vol. 1, R. Schmalensee and R. Willig (eds.), North Holland, Amsterdam.

Riordan, M. (1992), "Regulation and Preemptive Technology Adoption," Rand Journal of Economics, 23, 334-349.

Riordan, M. and D. J. Salant (1994), "Preemptive Adoptions of an Emerging Technology," Journal of Industrial Economics, 42, 247-261.

Ruiz-Aliseda, F. and P. Zemsky (2006), "Adoption is Not Development: First Mover Advantages in the Diffusion of New Technology," Insead Working Paper 2007/03/ST.

Sacco, D. (2008), "Is there a U-shaped Relation between Competition and Investment?," SOI Working Paper 0808, University of Zurich.

Scherer, F. (1967), "Market Structure and the Employment of Scientists and Engineers," American Economic Review, 57, 524-531.

Singh, N. and X. Vives (1984), "Price and Quantity Competition in a Differentiated Duopoly," Rand Journal of Economics, 15, 546-554.

Stenbacka, R. and M. Tombak (1994), "Strategic Timing of Adoption of New Technologies under Uncertainty," International Journal of Industrial Organization, 12, 387-411. 
Stoneman, P. (1983), The Economic Analysis of Technological Change, Oxford University Press, New York.

Symeonidis, G (2003), "Comparing Cournot and Bertrand Equilibria in a Differentiated Duopoly with Product R\&D," International Journal of Industrial Organization, 21, 3956.

Tishler, A. and I. Milstein (2009), "R\&D Wars and the Effects of Innovation on the Success and Survivability in Oligopoly Markets", International Journal of Industrial Organization, 27, 519-531.

Vives, X. (1985), "On the Efficiency of Bertrand and Cournot Equilibria with Product Differentiation," Journal of Economic Theory, 36, 166-175. 


\section{CESifo Working Paper Series}

for full list see www.cesifo-group.org/wp

(address: Poschingerstr. 5, 81679 Munich, Germany, office@cesifo.de)

2621 Yin-Wong Cheung and Xingwang Qian, The Empirics of China's Outward Direct Investment, April 2009

2622 Frédérique Bec and Christian Gollier, Assets Returns Volatility and Investment Horizon: The French Case, April 2009

2623 Ronnie Schöb and Marcel Thum, Asymmetric Information Renders Minimum Wages Less Harmful, April 2009

2624 Martin Ruf and Alfons J. Weichenrieder, The Taxation of Passive Foreign Investment Lessons from German Experience, April 2009

2625 Yao Li, Borders and Distance in Knowledge Spillovers: Dying over Time or Dying with Age? - Evidence from Patent Citations, April 2009

2626 Jim Malley and Ulrich Woitek, Technology Shocks and Aggregate Fluctuations in an Estimated Hybrid RBC Model, April 2009

2627 Jin Cao and Gerhard Illing, Endogenous Systemic Liquidity Risk, April 2009

2628 Thiess Buettner and Bjoern Kauder, Revenue Forecasting Practices: Differences across Countries and Consequences for Forecasting Performance, April 2009

2629 Håkan Selin, The Rise in Female Employment and the Role of Tax Incentives - An Empirical Analysis of the Swedish Individual Tax Reform of 1971, April 2009

2630 Nick Johnstone and Ivan Hascic, Environmental Policy Design and the Fragmentation of International Markets for Innovation, April 2009

2631 Spiros Bougheas, Richard Kneller and Raymond Riezman, Optimal Education Policies and Comparative Advantage, April 2009

2632 Jay Pil Choi and Heiko Gerlach, Multi-Market Collusion with Demand Linkages and Antitrust Enforcement, April 2009

2633 Thor O. Thoresen, Income Mobility of Owners of Small Businesses when Boundaries between Occupations are Vague, April 2009

2634 Guido Schwerdt and Amelie C. Wuppermann, Is Traditional Teaching really all that Bad? A Within-Student Between-Subject Approach, April 2009

2635 Kurt R. Brekke, Luigi Siciliani and Odd Rune Straume, Hospital Competition and Quality with Regulated Prices, April 2009

2636 Peter Diamond, Taxes and Pensions, April 2009 
2637 Shoshana Grossbard, How "Chicagoan” are Gary Becker's Economic Models of Marriage?, May 2009

2638 Roland Strausz, Regulatory Risk under Optimal Incentive Regulation, May 2009

2639 Holger Zemanek, Ansgar Belke and Gunther Schnabl, Current Account Imbalances and Structural Adjustment in the Euro Area: How to Rebalance Competitiveness, May 2009

2640 Harald Hau and Marcel Thum, Subprime Crisis and Board (In-)Competence: Private vs. Public Banks in Germany, May 2009

2641 Martin Halla, Mario Lackner and Friedrich G. Schneider, An Empirical Analysis of the Dynamics of the Welfare State: The Case of Benefit Morale, May 2009

2642 Balázs Égert, Infrastructure Investment in Network Industries: The Role of Incentive Regulation and Regulatory Independence, May 2009

2643 Christian Gollier, Expected Net Present Value, Expected Net Future Value, and the Ramsey Rule, May 2009

2644 Sören Blomquist and Håkan Selin, Hourly Wage Rate and Taxable Labor Income Responsiveness to Changes in Marginal Tax Rates, May 2009

2645 Dominique Demougin, Oliver Fabel and Christian Thomann, Implicit vs. Explicit Incentives: Theory and a Case Study, May 2009

2646 Francesco C. Billari and Vincenzo Galasso, What Explains Fertility? Evidence from Italian Pension Reforms, May 2009

2647 Kjell Arne Brekke, Karen Evelyn Hauge, Jo Thori Lind and Karine Nyborg, Playing with the Good Guys - A Public Good Game with Endogenous Group Formation, May 2009

2648 Guglielmo Maria Caporale and Luis A. Gil-Alana, Multi-Factor Gegenbauer Processes and European Inflation Rates, May 2009

2649 Henning Bohn, A Static Model for Voting on Social Security, May 2009

2650 Markus Haavio and Kaisa Kotakorpi, The Political Economy of Sin Taxes, May 2009

2651 Augusto de la Torre, María Soledad Martínez Pería and Sergio L. Schmukler, Drivers and Obstacles to Banking SMEs: The Role of Competition and the Institutional Framework, May 2009

2652 Tobias Lindhe and Jan Södersten, Dividend Taxation, Share Repurchases and the Equity Trap, May 2009

2653 Assaf Razin and Edith Sand, Migration-Regime Liberalization and Social Security: Political-Economy Effect, May 2009 
2654 Yin-Wong Cheung and Hiro Ito, A Cross-Country Empirical Analysis of International Reserves, May 2009

2655 Bart Cockx and Bruno Van der Linden, Flexicurity in Belgium. A Proposal Based on Economic Principles, May 2009

2656 Michael Melvin, Lukas Menkhoff and Maik Schmeling, Exchange Rate Management in Emerging Markets: Intervention via an Electronic Limit Order Book, May 2009

2657 Susanne Neckermann, Reto Cueni and Bruno S. Frey, What is an Award Worth? An Econometric Assessment of the Impact of Awards on Employee Performance, May 2009

2658 Steven Brakman, Harry Garretsen and Charles van Marrewijk, Economic Geography within and between European Nations: The Role of Market Potential and Density across Space and Time, May 2009

2659 Giovanni Facchini and Cecilia Testa, Reforming Legislatures: Is one House better than two?, May 2009

2660 Carsten Kowalczyk and Raymond Riezman, Trade Agreements, May 2009

2661 Oliver Falck, Stephan Heblich and Elke Luedemann, Identity and Entrepreneurship, May 2009

2662 Christian Lessmann and Gunther Markwardt, One Size Fits All? Decentralization, Corruption, and the Monitoring of Bureaucrats, May 2009

2663 Felix Bierbrauer, On the Legitimacy of Coercion for the Financing of Public Goods, May 2009

2664 Alessandro Cigno, Agency in Family Policy: A Survey, May 2009

2665 Claudia M. Buch and Christian Pierdzioch, Low Skill but High Volatility?, May 2009

2666 Hendrik Jürges, Kerstin Schneider, Martin Senkbeil and Claus H. Carstensen, Assessment Drives Learning: The Effect of Central Exit Exams on Curricular Knowledge and Mathematical Literacy, June 2009

2667 Eric A. Hanushek and Ludger Woessmann, Schooling, Cognitive Skills, and the Latin American Growth Puzzle, June 2009

2668 Ourania Karakosta, Christos Kotsogiannis and Miguel-Angel Lopez-Garcia, Does Indirect Tax Harmonization Deliver Pareto Improvements in the Presence of Global Public Goods?, June 2009

2669 Aleksandra Riedl and Silvia Rocha-Akis, Testing the Tax Competition Theory: How Elastic are National Tax Bases in OECD Countries?, June 2009 
2670 Dominique Demougin and Carsten Helm, Incentive Contracts and Efficient Unemployment Benefits, June 2009

2671 Guglielmo Maria Caporale and Luis A. Gil-Alana, Long Memory in US Real Output per Capita, June 2009

2672 Jim Malley and Ulrich Woitek, Productivity Shocks and Aggregate Cycles in an Estimated Endogenous Growth Model, June 2009

2673 Vivek Ghosal, Business Strategy and Firm Reorganization under Changing Market Conditions, June 2009

2674 Francesco Menoncin and Paolo M. Panteghini, Retrospective Capital Gains Taxation in the Real World, June 2009

2675 Thomas Hemmelgarn and Gaëtan Nicodème, Tax Co-ordination in Europe: Assessing the First Years of the EU-Savings Taxation Directive, June 2009

2676 Oliver Himmler, The Effects of School Competition on Academic Achievement and Grading Standards, June 2009

2677 Rolf Golombek and Michael Hoel, International Cooperation on Climate-Friendly Technologies, June 2009

2678 Martin Cave and Matthew Corkery, Regulation and Barriers to Trade in Telecommunications Services in the European Union, June 2009

2679 Costas Arkolakis, A Unified Theory of Firm Selection and Growth, June 2009

2680 Michelle R. Garfinkel, Stergios Skaperdas and Constantinos Syropoulos, International Trade and Transnational Insecurity: How Comparative Advantage and Power are Jointly Determined, June 2009

2681 Marcelo Resende, Capital Structure and Regulation in U.S. Local Telephony: An Exploratory Econometric Study; June 2009

2682 Marc Gronwald and Janina Ketterer, Evaluating Emission Trading as a Policy Tool Evidence from Conditional Jump Models, June 2009

2683 Stephan O. Hornig, Horst Rottmann and Rüdiger Wapler, Information Asymmetry, Education Signals and the Case of Ethnic and Native Germans, June 2009

2684 Benoit Dostie and Rajshri Jayaraman, The Effect of Adversity on Process Innovations and Managerial Incentives, June 2009

2685 Peter Egger, Christian Keuschnigg and Hannes Winner, Incorporation and Taxation: Theory and Firm-level Evidence, June 2009

2686 Chrysovalantou Milliou and Emmanuel Petrakis, Timing of Technology Adoption and Product Market Competition, June 2009 